\title{
Oxygen isotope analyses of fine silica grains using laser-extraction technique: Comparison with oxygen isotope data obtained from ion microprobe analyses and application to quartzite and silcrete cement investigation
}

\author{
Anne Alexandre ${ }^{\mathrm{a}, *}$, Isabelle Basile-Doelsch ${ }^{\mathrm{a}, \mathrm{b}}$, Corinne Sonzogni ${ }^{\mathrm{a}}$, Florence Sylvestre ${ }^{\mathrm{a}}$, \\ Claude Parron ${ }^{\mathrm{a}}$, Jean-Dominique Meunier ${ }^{\mathrm{a}}$, Fabrice Colin ${ }^{\mathrm{c}}$ \\ ${ }^{a}$ CEREGE, UMR 6635, CNRS, Université Paul Cézanne Aix-Marseille III, Europôle de l'Arbois, BP 80, 13545, Aix en Provence Cedex 04, France \\ b IRD-Réunion, LSTUR, BP 172, 97492 St-Denis Messagerie Cedex, France \\ ' IRD-Nouméa, 101 Promenade Roger Laroque-Anse Vata, BP A5-98848 Noumea Cedex, Nouvelle-Calédonie, France
}

Received 2 September 2005; accepted in revised form 3 March 2006

\begin{abstract}
The laser fluorination technique reported here for analyzing the oxygen isotope composition $\left(\delta^{18} \mathrm{O}\right)$ of fine quartz size fractions $50-20$, $20-10,10-5,5-2,2-1$ and $<1 \mu \mathrm{m}$ has been validated by comparison with the ion microprobe technique. It yields accurate $\delta^{18} \mathrm{O}$ data with an external precision better than $0.15 \%$. This is a significant methodological improvement for isotopic studies dealing with materials such as soil or biogenic oxides and silicates: particles are often too small and recovered in insufficient amount to be easily handled for ion microprobe analysis. Both techniques were used to investigate $\delta^{18} \mathrm{O}$ composition of a Cretaceous quartzite and silcrete sequence from the South-East of France. Quartzite cements average 31.04 $\pm 1.93 \%$. They formed from Mid-Cretaceous seawater. Higher in the series, silcretes cements average $26.66 \pm 1.36 \%$. They formed from Upper- or post-Upper-Cretaceous soil water and groundwater. Oxygen isotope data show that the silicification steps from one mineralogical phase to another and from one layer to another (including from an upper pedogenic silcrete to a lower groundwater silcrete) occurred in a closed or weakly evaporating hydrological system.
\end{abstract}

(C) 2006 Elsevier Inc. All rights reserved.

\section{Introduction}

Infra-red (IR) laser-heated fluorination techniques are now commonly used for analyzing the oxygen isotope compositions $\left(\delta^{18} \mathrm{O}\right)$ of grains of silicate and oxide minerals (e.g., Sharp et al., 2002). However several studies have shown that experimental problems occur during the laser heating of fine grain fractions. These include loss of ejecta and inconsistent $\delta^{18} \mathrm{O}$ values, and have prevented the application of laser-heated fluorination investigations to oxide and silica grains finer than $30-50 \mu \mathrm{m}$. Such fine size fractions are common in sandstones, chert and silcrete quartz cements, fine-grained sediment, soil oxides and biogenic sil-

\footnotetext{
* Corresponding author. Fax: +33442971540.

E-mail address: alexandre@cerege.fr (A. Alexandre).
}

ica particles such as phytoliths, diatoms and sponge spicules. The $\delta^{18} \mathrm{O}$ values of such materials are generally measured using conventional fluorination techniques which involve a large amount of sample (10 $\mathrm{mg}$, Alexandre et al., 2004) reacting slowly with $\mathrm{BrF}_{5}$. Laser-based techniques require small amount of sample $(0.5 \mathrm{mg}$, Crespin et al., 2005) and can be analyzed more quickly. Thus, analyzing fine powders of silicate and oxide minerals with an infra-red laser-heated fluorination technique would represent a significant methodological improvement. It would aid in understanding genesis of these phases and would enhance their use as quantitative proxies of paleo-waters and paleo-environments.

Fouillac and Girard (1996) first pointed out that measured $\delta^{18} \mathrm{O}$ values of quartz fractions finer than $75 \mu \mathrm{m}$ were lower when analyzed using a laser-heated fluorination 
technique than using conventional fluorination. Kirschner and Sharp (1997) proposed mixing powders finer than $30 \mu \mathrm{m}$ with $\mathrm{LiF}$ binder in order to prevent loss of ejecta. However making the pellets is an additional step to an already time-consuming method. Moreover, according to Kirschner and Sharp (1997) the sample chamber and adjacent line become coated with a $\mathrm{LiF}$ residue that necessitates periodic cleaning; thus to our knowledge, the binder method was not further developed. Spicuzza et al. (1998) after Valley et al. (1995) then described a rapid heating defocused laser beam technique using sufficient laser power that yielded good accuracy and precision when analyzing quartz size fractions finer than $50 \mu \mathrm{m}$. Up to now, there have been no investigations conducted on grain-size fractions finer than $30 \mu \mathrm{m}$.

In this paper, we report a $30 \mathrm{~W} \mathrm{CO}$ IR laser heating protocol that leads to good precision and reproducibility of $\delta^{18} \mathrm{O}$ analyses of quartz size fractions $50-20,20-10$, $10-5,5-2,2-1$ and $<1 \mu \mathrm{m}$. The laser fluorination technique applied to fine quartz grains was validated by comparison with results using the ion microprobe technique. Both techniques have been used to investigate the $\delta^{18} \mathrm{O}$ composition of micro- $(1-5 \mu \mathrm{m}$ or $2-5 \mu \mathrm{m})$, granular and fibrous crypto$(<1$ or $2 \mu \mathrm{m})$ crystalline quartz cements of a quartzite and silcrete sequence from the Southeast of France. Processes of formation of the quartzite and silcrete sequence have been inferred from $\delta^{18} \mathrm{O}$ data, and $\delta^{30} \mathrm{Si}$ results recently obtained by Basile-Doelsch et al. (2005) on the same sequence.

\section{Geological setting, sample description and analytical methods}

\subsection{Geological setting}

The sandstones series of Apt (South-East of France) (Triat and Parron, 1976; Sabouraud and Parron, 1977; Parron and Guendon, 1985; Basile-Doelsch et al., 2005) (Fig. 1) has an inferred age of Mid-Cretaceous (Albian to Lower Cenomanian). Sedimentation occurred in seawater

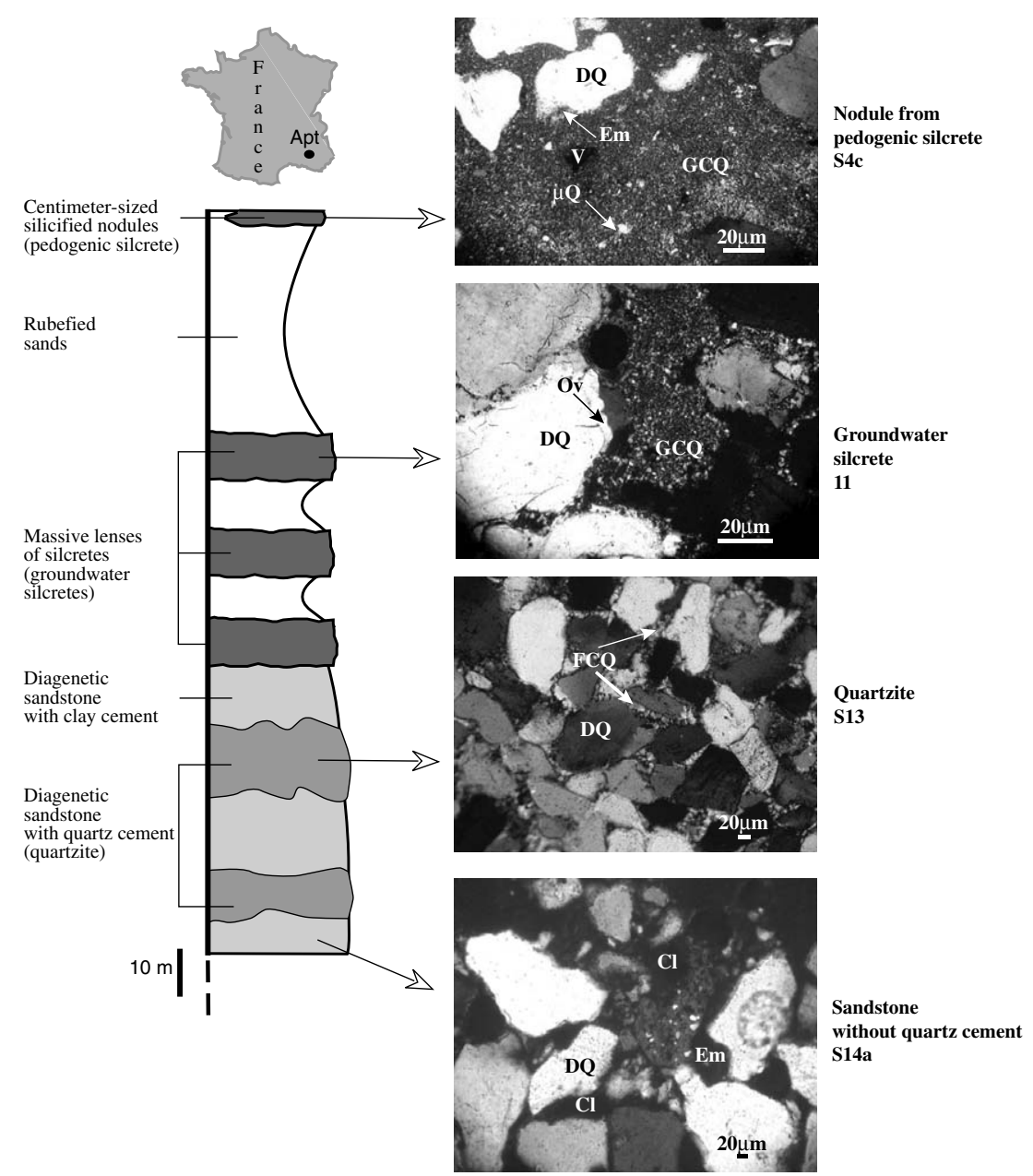

Fig. 1. Location map and schematic section of the Apt series (modified from Basile-Doelsch et al., 2005) showing the sandstone, quartzite and silcrete samples analyzed in this study. Photomicrographs of silcrete (S4c and 11), quartzite (S13) and sandstone (S14a) samples showing detrital quartz (DQ), overgrowths $(\mathrm{Ov})$, embayments $(\mathrm{Em})$, micro-crystalline quartz $(\mu \mathrm{Q})$, granular crypto-crystalline quartz (GCQ), fibrous crypto-crystalline quartz (FCQ), clays $(\mathrm{Cl})$ and voids $(\mathrm{V})$, are associated. 
(Cretaceous Alpine Sea), as indicated by the occurrence of syn-sedimentary glauconite. Deposition was followed by diagenetic carbonate and silica cementation of detrital quartz leading to the formation of sandstones. When the cement and detrital grains of sandstones are made of quartz, the sandstones are also called quartzites. During Upper-Cretaceous time, the Durance uplift exhumed the glauconitic sandstones and quartzites where they were subjected to weathering under a wet tropical climate. In the upper part of the series, weathering of quartz marine cements and glauconite led to the formation of red- to yellow-ochre sands composed of detrital quartz associated with kaolinite, goethite and hematite. At the top of the series a silcrete comprising centimeter-sized silicified nodules in a cement of clays is present. Massive lenses of silcretes, made of detrital quartz in micro and crypto-crystalline quartz cement, developed below, in different layers of the rubefied sands. No geochronologic techniques are available for the accurate dating of these Upper- or post-Upper Cretaceous silcretes (Watchman and Twidale, 2002). Analysis of fluid inclusions of a silcrete cement showed that the cementing fluid was low temperature $\left(<40^{\circ} \mathrm{C}\right)$ fresh water (Sabouraud and Parron, 1977). On the basis of microscopic features in the samples, the vertical superposition of silcretes was interpreted as having formed from soil water in its upper portions (pedogenic silcrete) and from successively deepening levels of the water table in the lower portions (groundwater silcretes) (Basile-Doelsch et al., 2005).

\subsection{Sample descriptions}

Microscopic observations of thin sections (Fig. 1) were done to determine the mineralogical composition of the sandstones, quartzites and silcretes. On the basis of field and microscopic observations, three sets of samples were collected (Fig. 1). One sample of sandstone without quartz cement (S14a); samples of quartzites from two levels (S5b and S13), partly characterized by non-weathered glauconite; and three samples of silcretes from three levels (11, S14b and S4c) distinguished by the occurrence of weathered glauconite or lack of glauconite. All samples exhibit a grain-supported fabric, except for S14a and S4c which exhibit a floating fabric. From bottom to top, samples are described as follows (Fig. 1).

\subsubsection{Sandstone without quartz cement}

S14a (site of Gorgues, level VII), a matrix supported sandstone, consists of $100-500 \mu \mathrm{m}$ size rounded and partly embayed (Em) detrital quartz (DQ) grains devoid of overgrowths $(\mathrm{Ov})$, surrounded by a micron-scale brown coating, in a cement of clays $(\mathrm{Cl})$ containing titanium oxide.

\subsubsection{Quartzite}

S5b (site of Gorgues, level II), a grain-supported quartzite, is made of $50-300 \mu \mathrm{m}$ size irregular detrital quartz grains devoid of overgrowths, in places surrounded by a micron-scale brown coating and non-weathered glauconite grains, in a cement of fibrous crypto-crystalline quartz (FCQ) (also defined as chalcedony).

S13 (site of Couloubrier, below level VII), a grain-supported quartzite, is made of $50-300 \mu \mathrm{m}$ size rounded detrital quartz grains devoid of overgrowths, and juxtaposed against non-weathered glauconite grains in a cement of fibrous crypto-crystalline quartz and weathered glauconite.

\subsubsection{Silcretes}

Sample 11 (site of Istrane, higher level IV), a grain-supported silcrete, is made of 50-500 $\mu \mathrm{m}$ size rounded detrital quartz grains with overgrowths, which are in places surrounded by a brown coating, in a cement of granular crypto-crystalline quartz (GCQ) and weathered glauconite. Micro-crystalline quartz $(\mu \mathrm{Q})$ occurs in cracks.

S14b (Gorgues, level VII), a grain-supported silcrete, is made of 50-300 $\mu \mathrm{m}$ size rounded detrital quartz grains with overgrowths, and surrounded by a brown coating, in a cement of granular crypto-crystalline quartz. No glauconite was observed.

S4c (Istrane, upper level), a matrix-supported silcrete, shows, at the macroscopic scale, pedogenic features such as silicified nodules and silicified root porosity. Nodules are made of $50-150 \mu \mathrm{m}$ size rounded detrital quartz grains with embayments, in a cement of micro- and granular crypto-crystalline quartz ( $\mu \mathrm{Q}$ and GCQ). No glauconite was observed.

\subsection{Analytical methods}

\subsubsection{Separation and concentration of micro-, granular crypto- and fibrous crypto-crystalline quartz size fractions}

In an attempt to concentrate the cement phases, size fractionation of the sample was done following a procedure developed by Lee and Savin (1985), and later used by Girard and Deynoux (1991), Graham et al. (1996), Girard et al. (2001) and Alexandre et al. (2004). Samples were gently ground in water to preserve as much as possible the original grain-size of constituents. Iron oxides were reduced using sodium citrate and sodium dithionite. Residual amorphous material was removed by boiling in hydrochloric acid until the solution became clear. Samples were treated with 7\% hydrofluoric acid at room temperature in an ultrasonic bath for six days in order to weaken grains along the core-cement interface and facilitate the separation of the cement from the detrital grains. This step was repeated two or three times. The purity of the quartz samples was checked under the optical microscope and by Xray diffraction (XRD). After rinsing, the samples were sieved at 200, 100 and $50 \mu \mathrm{m}$. The $<50 \mu \mathrm{m}$ size fraction was separated into $50-20,20-10,10-5,5-2,2-1$ and $<1 \mu \mathrm{m}$ size fractions using a centrifuge. Particles finer than $<1 \mu \mathrm{m}$ were recovered for sample S4c only. Efficiency of the size separations was checked under optical microscope. The 5-2 $\mu \mathrm{m}$ and coarser size fractions always contain significant amounts of particles coarser than the nominal upper limit of the fraction. Size fractions $2-1 \mu \mathrm{m}$ and 
$<1 \mu \mathrm{m}$ were correctly separated. Samples S13 (quartzite), S14b, 11 and S4c (silcretes) were processed following the procedure described above. Sample S14a was not processed or analyzed by laser-fluorination, because its cement is made of clays. Similarly, we were unable to analyze the cement in sample S5b because the large concentration of iron oxides in this cement could not be successfully removed.

\subsubsection{Necessity of an equilibration procedure of the quartz cement prior to isotopic analysis}

The occurrence of a significant amount of exchangeable oxygen in hydroxyl-bearing silicate phases, particularly crypto-crystalline quartz, may require one to perform isotopic analysis via an isotopic equilibration technique such as that developed by Labeyrie and Juillet (1982). Equilibration of exchangeable oxygen was performed on samples $\mathrm{S} 4 \mathrm{c}<2 \mu \mathrm{m}$ (granular crypto-crystalline cement) and $\mathrm{S} 13<2 \mu \mathrm{m}$ which contain some fibrous crypto-crystalline quartz cement. The resulting $\delta^{18} \mathrm{O}$ values $(27.2 \pm 0.2 \% \pm$ for $\mathrm{S} 4 \mathrm{c}<2 \mu \mathrm{m} ; 22.03 \%$ for $\mathrm{S} 13<2 \mu \mathrm{m}$ ) were similar to $\delta^{18} \mathrm{O}$ values obtained without equilibration $(27.1 \pm 0.2 \%$ for $\mathrm{S} 4 \mathrm{c}<2 \mu \mathrm{m} ; 22.05 \pm 0.2 \%$ for $\mathrm{S} 13<2 \mu \mathrm{m})$. We conclude that the crypto-crystalline quartz cements were not hydrated to the extent that requires an equilibration step. This is consistent with the conclusion based on Fouriertransformed-infra-red (FT-IR) data by Alexandre et al. (2004) for fibrous crypto-crystalline quartz of an Australian silcrete. This is also consistent with XRD pattern of sample $\mathrm{S} 13<2 \mu \mathrm{m}$ that only shows peaks attributed to well crystallized quartz and no obvious diffuse intensity, large half width or diffuse peaks with $d$-spacing between 0.43 and $0.28 \mathrm{~nm}$, characteristic of silica minerals with structural disorder and/or low crystallite size (Flörke et al., 1991).

\subsubsection{Oxygen isotope analysis of fine silica grains using laser extraction technique}

Molecular $\mathrm{O}_{2}$ was extracted from quartz using a laser extraction technique similar to that described by Sharp (1990). The oxygen isotope ratio was measured using $\mathrm{O}_{2}$ gas and a ThermoQuest Finnigan Delta Plus mass spectrometer at CEREGE (Aix-en-Provence, France). The originality of this study lies in analysis of fine quartz powders ranging from 200 to $1 \mu \mathrm{m}$ (Fig. 2):

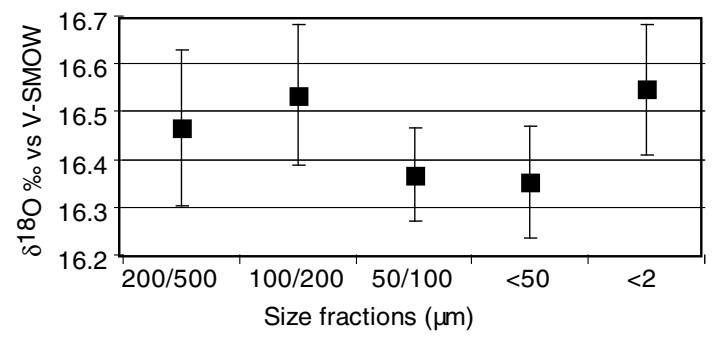

Fig. 2. Average $\delta^{18} \mathrm{O}$ and reproducibility (error bars) of size fractions of the laboratory quartz standard "Boulangé" obtained with the laser fluorination technique, CEREGE. The overall average value is $16.46 \% \pm 0.15$ vs V-SMOW (76 analyses).
A Merchanteck $30 \mathrm{~W} \mathrm{CO}$ IR laser was used. Thirty three samples of $1.5 \mathrm{mg}$ were loaded in a nickel sample holder, dried at $105^{\circ} \mathrm{C}$ for $1 \mathrm{~h}$ and pre-fluorinated in a vacuum line for $1 \mathrm{~h}$. In an atmosphere of 100 mbars of $\mathrm{BrF}_{5}$ samples were preheated with a $0.1 \mathrm{~W}$ laser beam with a diameter of $2000 \mu \mathrm{m}$ for $20 \mathrm{~s}$. The power of the $2000 \mu \mathrm{m}$ of diameter laser beam was then increased up to $12-13 \mathrm{~W}$ and samples were heated starting at the center and slowly moving the laser beam in progressively larger concentric circles until a bowl of liquid silica formed. The laser beam was then focused to a diameter of first $1000 \mu \mathrm{m}$ and then to $200 \mu \mathrm{m}$. Laser emission was stopped when all particles disappeared in the gas phase. This protocol avoids ejection of a portion of the sample. Replicate analyses of the international standard NBS $28(120-250 \mu \mathrm{m})$ gave an average of $9.6 \pm 0.15 \%(1 \sigma)$ vs V-SMOW. Seventy-six analyses run over 12 weeks of a laboratory quartz standard ("Boulangé") of 200-100, 100-50, 50-2 and 2-1 $\mu \mathrm{m}$ yielded an average value of $16.46 \%$ and an external reproducibility of $\pm 0.15 \%$ ( $1 \mathrm{~s}$ ), with no relationship between measured $\delta^{18} \mathrm{O}$ values and grain size (Fig. 2).

\subsubsection{In situ oxygen isotope analysis using the ion microprobe}

The oxygen isotope ratios of detrital quartz, overgrowths, micro-, granular crypto- and fibrous crypto-crystalline quartz were measured using the CAMECA IMS 1270 microprobe (secondary ion mass spectrometry (SIMS)), with a 40-50 $\mu \mathrm{m}$ spot size, at CRPG (Nancy, France) (Gurenko et al., 2001). Internal precision of $\pm 0.2 \%$ o $\left(1 \sigma_{n}\right)$ was obtained when analyzing quartz standards and samples. Replicate analyses of internal quartz standards gave an external reproductibility of $\pm 0.3 \%$ $(1 \sigma)$. Locations of analyzed craters were identified under the optical microscope after the SIMS session. Data obtained from craters that included several mineralogical phases (e.g., detrital quartz and overgrowth, overgrowth and micro-crystalline quartz,... etc.) were not considered further.

\section{Results}

\section{1. $\delta^{18} \mathrm{O}$ data obtained on separated size fractions using the laser-fluorination technique}

Average $\delta^{18} \mathrm{O}$ compositions of the size fractions of samples S13 (quartzite), S14b, 11 and S4c (silcretes), obtained after grain size separation and laser fluorination are given Fig. 3 and Table 1. Standard deviations $(\sigma)$ higher than $0.15 \%$ likely indicate heterogeneity of the extracted material.

The $\delta^{18} \mathrm{O}$ values of the four samples increase with decreasing size fraction, consistent with progressive increases in the authigenic quartz content in the finer fractions. The $\delta^{18} \mathrm{O}$ values of the coarsest fraction range from $17.3 \pm 0.01 \%$ (S14b) to $21.3 \pm 0.13 \%$ o (S4c) suggesting that the samples with the highest $\delta^{18} \mathrm{O}$ values contain a mixture 


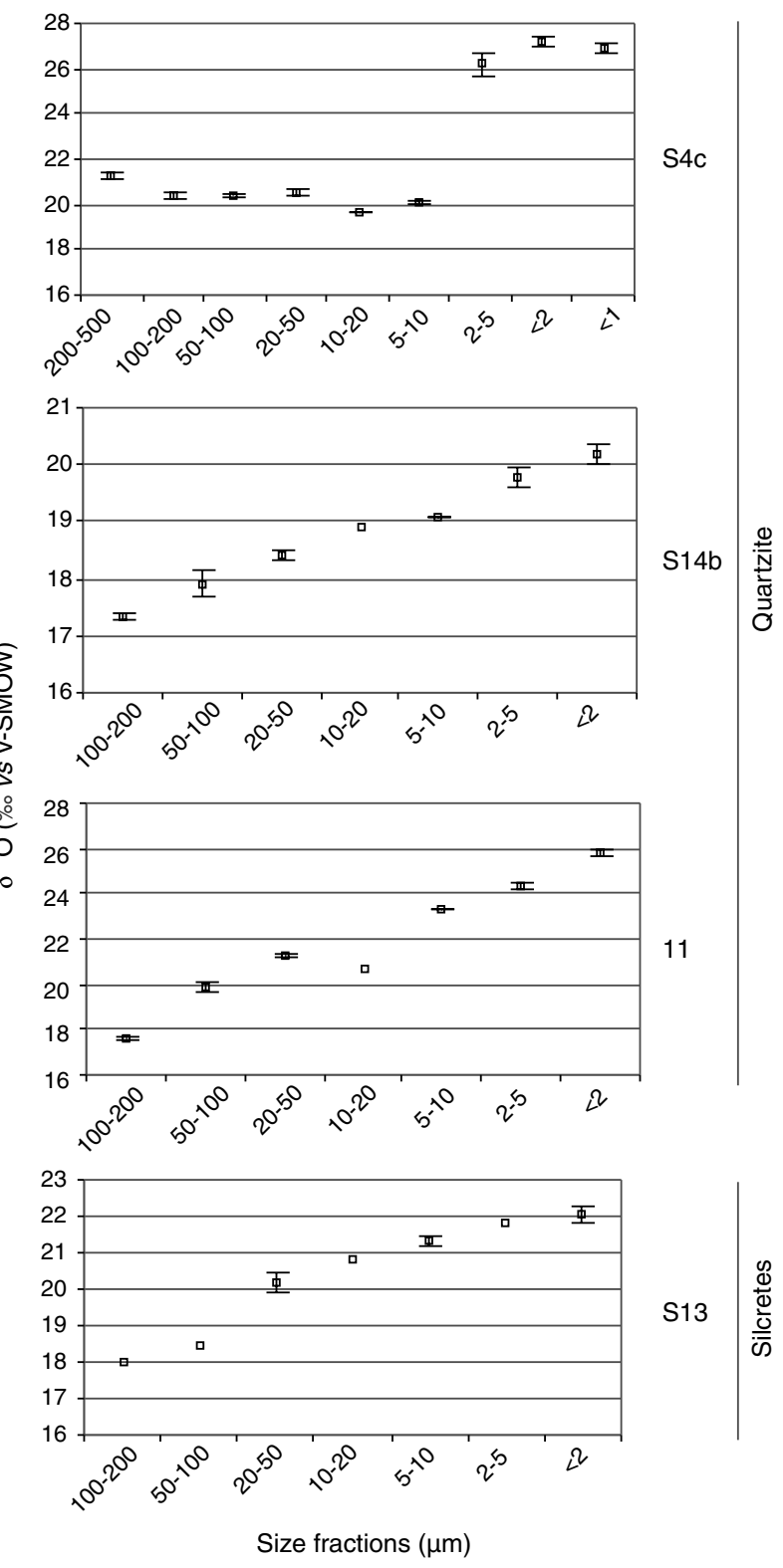

Fig. 3. The $\delta^{18} \mathrm{O}$ composition of size fractions extracted from quartz cements of the quartzite and silcrete sequence obtained with the laserfluorination technique, CEREGE. No error bars (reproducibility) are displayed for samples analyzed only once.

of detrital quartz $\left(\delta^{18} \mathrm{O}\right.$ values ranging from 6.4 to $20 \%$ according to Garlick and Epstein, 1967; Savin and Epstein, 1970; Clayton et al., 1972; Eslinger et al., 1973; Blatt, 1986; Graham et al., 1996) and authigenic quartz $\left(\delta^{18} \mathrm{O}\right.$ values ranging from 20 to $32 \%$ according to Savin and Epstein, 1970; Graham et al., 1996; Kolodony and Epstein, 1976; Bird et al., 1992; Abdel-Wahab et al., 1998; Webb and Golding, 1998; Alexandre et al., 2004).

The $\delta^{18} \mathrm{O}$ values of the $2-5 \mu \mathrm{m}$ size fractions range from $19.8 \pm 0.15 \%$ (S14b) to $26.18 \pm 0.48 \%$ (S4c). Those samples with the lowest $\delta^{18} \mathrm{O}$ values, while predominantly authigenic, contain some detrital quartz as well. The $\delta^{18} \mathrm{O}$ values of the $2-1 \mu \mathrm{m}$ size fractions range from
$20.19 \pm 0.16 \%$ (S14b) to $27.2 \pm 0.2 \%$ (11), while the $\delta^{18} \mathrm{O}$ value of the $<1 \mu \mathrm{m}$ fraction (S4c) is $26.8 \pm 0.17 \%$.

\section{2. $\delta^{18} \mathrm{O}$ data obtained from in situ ion microprobe analysis}

The $\delta^{18} \mathrm{O}$ values of detrital quartz, overgrowths, micro-, granular crypto- and fibrous crypto-crystalline quartz of the sandstone and quartzite samples are given in Fig. 4. Averages are given Table 1. Some phases such as the micro-crystalline quartz of sample S14b and overgrowths of sample 11 could not be analyzed because of the lack of visibility of the grain boundaries.

Detrital quartz show a large range of $\delta^{18} \mathrm{O}$ values although the ranges are essentially all the same (Fig. 4), with $\delta^{18} \mathrm{O}$ averages in individual samples (Table 1) ranging from $8.29 \pm 0.3 \%$ o (S14b) to $13.38 \pm 0.14 \%$ (S4c). Moreover, variability of $\delta^{18} \mathrm{O}$ values occurs at the scale of single detrital grains (e.g., three $\delta^{18} \mathrm{O}$ values measured on one detrital grain from S14a: 7.46, 8.17 and $14.31 \pm 0.3 \%$ ). Such significant intra-grain variability has also been reported by Graham et al. (1996) for detrital quartz and by Aléon et al. (2002) for eolian quartz from several sources.

Authigenic overgrowth, and micro- and granular crypto-crystalline quartz of samples 11, S14b and S4c (silcretes) give very similar average $\delta^{18} \mathrm{O}$ values ranging from $25.8 \pm 1.14 \%$ to $27.57 \pm 0.91 \%$. No obvious relationships were found among average $\delta^{18} \mathrm{O}$ values, location of craters close or far from detrital grains or voids. Because a combination of sample heterogeneity and analytical uncertainties lead to a relatively high standard deviations of $\delta^{18} \mathrm{O}$ values from a single phase, it does not appear reasonable to interpret as significant a ca. $1 \% \delta^{18} \mathrm{O}$ average variation from one phase to another (e.g., between S4c micro-crystalline quartz and $\mathrm{S} 4 \mathrm{c}$ granular crypto-crystalline quartz).

Fibrous crypto-crystalline quartz constituting the cement of samples S5b and S13 (quartzites) reach values of $30.99 \pm 0.54 \%$ and $31.09 \pm 2.60 \%$. Once again, no obvious relationship was found between $\delta^{18} \mathrm{O}$ value and location of the phase close or far from detrital grains or voids.

Finally, two groups of siliceous cements can be distinguished: (1) cements made of overgrowths, micro- and granular crypto-crystalline quartz of samples 11, S14b and $\mathrm{S} 4 \mathrm{c}$ (silcretes) which have similar $\delta^{18} \mathrm{O}$ values averaging $26.66 \pm 1.36 \%$, regardless of the mineralogical phase; (2) cements made of fibrous crypto-crystalline quartz of samples S5b and S13 (quartzites) which have similar $\delta^{18} \mathrm{O}$ values averaging $31.04 \pm 1.93 \%$. These values are close to the ones determined by Kolodony et al. (2005) for a chert breccia where the fragments of chert formed from seawater $\left(\delta^{18} \mathrm{O}\right.$ value around $32 \%$ ) and the breccia matrix formed from fresh water $\left(\delta^{18} \mathrm{O}\right.$ value around $26 \%$ o $)$.

\subsection{Comparison of data between the two techniques}

Comparison of data obtained with both techniques (Table 1) shows that when cements are fibrous cryptocrystalline quartz (sample S13), $\delta^{18} \mathrm{O}$ values measured on 
Table 1

Comparison of $\delta^{18} \mathrm{O}$ data obtained from in situ microprobe analyses and from the laser fluorination technique analyses applied to small size fractions

\begin{tabular}{|c|c|c|c|c|c|c|c|c|c|}
\hline \multicolumn{5}{|c|}{ In situ CRPG ion microprobe (Nancy, France) } & \multicolumn{5}{|c|}{ Laser fluorination of micrometric fractions CEREGE (Aix en Provence, France) } \\
\hline \multirow[t]{2}{*}{ Sample \# } & \multirow[t]{2}{*}{ Mineralogy } & \multicolumn{2}{|l|}{$\delta^{18} \mathrm{O}$} & \multirow[t]{2}{*}{$n$} & \multirow[t]{2}{*}{ Sample \# } & \multirow[t]{2}{*}{ Mineralogy } & \multicolumn{2}{|c|}{$\delta^{18} \mathrm{O}$} & \multirow[t]{2}{*}{$\bar{n}$} \\
\hline & & $(\%$ vs V-SMOW $)$ & $1 \sigma$ & & & & $(\%$ vs V-SMOW $)$ & $1 \sigma$ & \\
\hline \multicolumn{10}{|l|}{ Silcretes } \\
\hline \multirow[t]{5}{*}{$\mathrm{S} 4 \mathrm{c}$} & DQ & 13.38 & 0.14 & 13 & & & & & \\
\hline & $\mu \mathrm{Q}$ & 26.65 & 0.69 & 3 & $\mathrm{~S} 4 \mathrm{c} 5-10 \mu \mathrm{m}$ & & 20.05 & 0.04 & 2 \\
\hline & GCQ & 27.57 & 0.91 & 22 & $\mathrm{~S} 4 \mathrm{c} 2-5 \mu \mathrm{m}$ & $\mu \mathrm{Q}, \mathrm{GCQ}$ & 26.18 & 0.48 & 2 \\
\hline & & & & & $\mathrm{S} 4 \mathrm{c}<2 \mu \mathrm{m}$ & & 27.20 & 0.20 & 4 \\
\hline & & & & & $\mathrm{S} 4 \mathrm{c}<1 \mu \mathrm{m}$ & & 26.88 & 0.17 & 3 \\
\hline \multirow[t]{4}{*}{11} & DQ & 10.84 & 1.90 & 6 & & & & & \\
\hline & $\mu \mathrm{Q}$ (crack) & 25.91 & 0.75 & 5 & $115-10 \mu \mathrm{m}$ & & 23.30 & & \\
\hline & GCQ & 25.80 & 1.14 & 10 & $112-5 \mu \mathrm{m}$ & $\mathrm{Ov}, \mu \mathrm{Q}, \mathrm{GCQ}$ & 24.35 & & \\
\hline & & & & & $11<2 \mu \mathrm{m}$ & & 25.80 & 0.01 & 2 \\
\hline \multirow[t]{5}{*}{$\mathrm{S} 14 \mathrm{~b}$} & DQ & 8.29 & 0.34 & 1 & & & & & \\
\hline & Ov & 26.34 & 0.29 & 6 & & & & & \\
\hline & & & & & $\mathrm{S} 14 \mathrm{~b} 2-5 \mu \mathrm{m}$ & $\mathrm{Ov}, \mu \mathrm{Q}$ & 19.79 & 0.15 & 2 \\
\hline & & & & & & & 20.19 & 0.16 & 4 \\
\hline & Average $\mu \mathrm{Q}, \mathrm{GCQ}, \mathrm{Ov}$ & 26.66 & 1.36 & 46 & & & & & \\
\hline \multicolumn{10}{|l|}{ Quartzites } \\
\hline \multirow[t]{2}{*}{ S13 } & DQ & 10.02 & 1.69 & 5 & $\mathrm{~S} 132-5 \mu \mathrm{m}$ & & 21.85 & & 1 \\
\hline & FCQ & 31.09 & 2.60 & 9 & $\mathrm{~S} 13<2 \mu \mathrm{m}$ & FCQ & 22.05 & 0.19 & 2 \\
\hline \multirow[t]{3}{*}{$\mathrm{S} 5 \mathrm{~b}$} & DQ & 10.48 & 1.62 & 4 & & & & & \\
\hline & FCQ & 30.99 & 0.54 & 7 & & & & & \\
\hline & Average $\mu \mathrm{Q}, \mathrm{GCQ}, \mathrm{Ov}$ & 31.04 & 1.93 & 16 & & & & & \\
\hline \multicolumn{10}{|c|}{ Sandstone without quartz cement } \\
\hline $\mathrm{S} 14 \mathrm{a}$ & $\mathrm{DQ}$ & 11.46 & 2.36 & 20 & & & & & \\
\hline
\end{tabular}

DQ: detrital quartz; Ov: overgrowth; $\mu$ Q: micro-crystalline quartz; GCQ: granular crypto-crystalline quartz; FCQ: fibrous crypto-crystalline quartz.

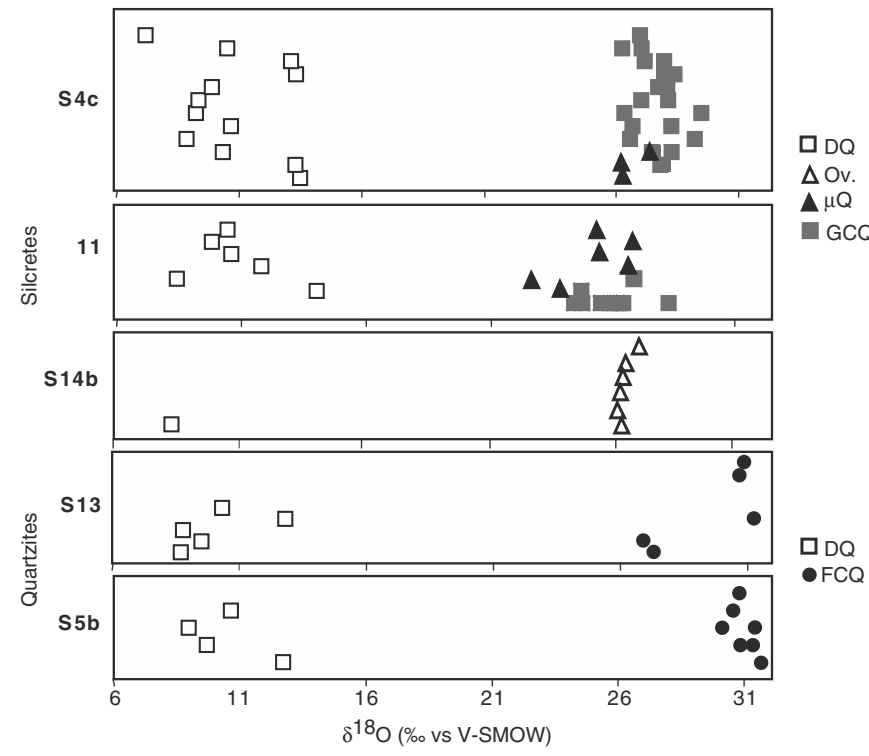

Fig. 4. The $\delta^{18} \mathrm{O}$ composition of detrital quartz (DQ), overgrowths (Ov), micro-crystalline quartz $(\mu \mathrm{Q})$, granular crypto-crystalline quartz (GCQ) and fibrous crypto-crystalline quartz (FCQ) obtained from in situ ion microprobe analysis, CRPG. Internal precision $(0.3 \%)$ is included in the points.

the $2-1 \mu \mathrm{m}$ size fractions using laser-fluorination $(22.05 \pm$ $0.19)$ are far lower than $\delta^{18} \mathrm{O}$ values measured in situ with the ion microprobe $(31.09 \pm 2.6)$, certainly due to an admixture of detrital quartz in the samples analyzed by laser fluorination.

When cements are made of micro- and granular cryptocrystalline quartz ( $\mathrm{S} 4 \mathrm{c}$ and 11$), \delta^{18} \mathrm{O}$ values measured on the 2-5 $\mu \mathrm{m}$ size fractions by laser-fluorination $(26.18 \pm 0.48 \%(\mathrm{~S} 4 \mathrm{c})$ and $24.35 \%$ (11)) are similar to or a bit lower than $\delta^{18} \mathrm{O}$ values measured in situ for micro-crystalline quartz with the ion microprobe $(26.65 \pm 0.69 \%$ o $(\mathrm{S} 4 \mathrm{c})$, $25.91 \pm 0.75 \%$ o (11)). $\delta^{18} \mathrm{O}$ values measured for the $<2 \mu \mathrm{m}$ size fractions by laser-fluorination $(27.2 \pm 0.2 \%$ oo $(\mathrm{S} 4 \mathrm{c}<2$ $\mu \mathrm{m}) ; \quad 26.88 \pm 0.17 \% \quad(\mathrm{~S} 4 \mathrm{c}<1 \mu \mathrm{m}) \quad$ and $\quad 25.8 \pm 0.01 \%$ $(11<2 \mu \mathrm{m}))$ are similar to $\delta^{18} \mathrm{O}$ values measured in situ for granular crypto-crystalline quartz with the ion microprobe $(27.57 \pm 0.91 \%$ oo $(\mathrm{S} 4 \mathrm{c}), 25.8 \pm 1.14 \%$ oo $(11))$.

\section{Discussion}

\subsection{Reliability of laser extraction for analyzing microscopic silica grains}

The laser protocol reported here allows analysis of oxygen isotope ratios of separated quartz size-fractions finer than $30,20,10,5$ and $2 \mu \mathrm{m}$ with a reproducibility of $\pm 0.15 \%$.

Similarity between $\delta^{18} \mathrm{O}$ data obtained with the laser fluorination technique on the $<2-1 \mu \mathrm{m}$ quartz size-frac- 
tions and with the ion microprobe on granular crypto-crystalline quartz support the conclusion that data obtained by both techniques are accurate.

Thirty-three analyses of $1.5 \mathrm{mg}$ of fine powders can be made over four days. Up to now, because of methodological problems such as ejection of powder during laser heating, these size fractions were still processed using conventional time consuming bulk fluorination procedures that required much larger amounts of sample.

\subsection{Efficacy of concentration of micro-, granular crypto- and fibrous crypto-crystalline quartz size-fractions}

(1) Isotope data indicate that the separation method used here did not provide pure concentrates of fibrous crypto-crystalline quartz.

(2) All size fractions coarser than $5 \mu \mathrm{m}$ contain a mixture of authigenic and detrital quartz and do not effectively concentrate micro-crystalline quartz. Micro-crystalline quartz is better concentrated in the $2-5 \mu \mathrm{m}$ size fraction. Alexandre et al. (2004) followed the same concentration protocol in an attempt to concentrate an Australian silcrete cement made of fibrous crypto- and micro-crystalline quartz. The $<2 \mu \mathrm{m}$ quartz fraction of their sample contained about $4 \%$ of detrital quartz as indicated by cathodoluminescence (CL). Detrital high-temperature quartz typically exhibits bright luminescence, while authigenic low-temperature quartz is typically non- or weakly luminescent (Sprunt and Nur, 1981). The $\delta^{18} \mathrm{O}$ analysis using the conventional fluorination method and mass-balance calculation led to a calculated $\delta^{18} \mathrm{O}$ value of the cement ranging between 24.8 and $25.8 \%$. New in situ $\delta^{18} \mathrm{O}$ analyses of this silcrete sample obtained using the ion microprobe during the present study yielded $\delta^{18} \mathrm{O}$ values of $30.25 \pm 1.78 \%(n=6)$ and $25.8 \pm 0.48 \%(n=4)$, respectively, for the fibrous crypto-crystalline quartz cement and for the micro-crystalline quartz cement. This new result confirms that the separation protocol is very suitable for concentration of micro-crystalline quartz but inadequate to concentrate fibrous crypto-crystalline quartz. The paleo-environmental interpretations presented by Alexandre et al. (2004) are not in doubt but should be applied to the micro-crystalline phase of the Australian silcrete cement only.

(3) Granular crypto-crystalline quartz is efficiently concentrated in the $<2-1 \mu \mathrm{m}$ size-fraction.

\subsection{Implications for the cementation processes of quartzites and silcretes of the Apt series}

The $\delta^{18} \mathrm{O}$ composition of a mineral reflects the $\delta^{18} \mathrm{O}$ value of water from which it formed and the temperature of formation. On this basis, hydrological constraints leading to cementation processes can be documented from the $\delta^{18} \mathrm{O}$ values of quartzites and silcretes cements studied in this paper.

\subsubsection{Quartzites}

Cements from samples S5b and S13 (quartzites), made of fibrous crypto-quartz show similar $\delta^{18} \mathrm{O}$ composition averaging $31.04 \pm 1.93 \%$ o (Table 1). This value is typical of shallow sea cherts (Sharp et al., 2002; Kolodony et al., 2005), in agreement with interpretations previously drawn from field and petrographic observations of a marine origin (Parron et al., 1976).

\subsubsection{Silcretes}

The sequence of formation of quartz polymorphs determined in this study is typical of silcrete cements and is commonly interpreted as resulting from successive dissolution/ re-crystallization stages with associated leaching of impurities (Thiry and Millot, 1987). This process was also proposed by Basile-Doelsch et al. (2005) who studied silicon isotope ratios $\left(\delta^{30} \mathrm{Si}\right)$ of micro- and granular crypto-crystalline quartz of several silcrete samples of the Apt Series. They found a shift in $\delta^{30} \mathrm{Si}$ of about $-2 \%$ from micro- to granular crypto-crystalline quartz and from one silcrete level to another. Successive dissolution/re-crystallization can lead to the formation of highly fractionated quartz cements $\left(\delta^{30} \mathrm{Si}\right.$ of $\left.-7.5 \%\right)$.

Given the large dispersion of $\delta^{18} \mathrm{O}$ signatures among a single phase (up to $\pm 1.14 \%$ in granular crypto-crystalline quartz of sample 11) and the analytical uncertainty $( \pm 0.3 \%)$, the measured $\delta^{18} \mathrm{O}$ values of overgrowths, granular crypto-crystalline quartz and micro-crystalline quartz and from one silcrete layer to another may be regarded as similar $(26.66 \pm 1.36 \%$; Table 1$)$. This result suggests that changes in the silicification process that caused shifts from one mineralogical phase to another and from one silcrete layer to another (including from upper pedogenic silcrete to lower groundwater silcrete) occurred in a closed hydrological system that experienced only small variation in the $\delta^{18} \mathrm{O}$ value of water.

Alternatively, the variations in $\delta^{18} \mathrm{O}$ values of quartz of about $\pm 1 \%$ around $26 \%$ (range of variations in a single phase, from a phase to another, and from a layer to another) may be interpreted in term of changes in temperature and/or water $\delta^{18} \mathrm{O}$ values: (1) Assuming that the $\delta^{18} \mathrm{O}$ value of the silcrete-forming water was constant, and using the oxygen isotope fractionation factors between quartz and water (Knauth and Epstein, 1976; Matsuhisa et al., 1979), the $\delta^{18} \mathrm{O}$ variations among the cements range from 25.3 to $28.02 \%$, corresponding to a temperature range of more than $8^{\circ} \mathrm{C}$. Such a large temperature change occurred on a million-year time scale during Upper-Cretaceous time and later but is difficult to imagine on a shorter time scale. (2) Assuming that temperature remained constant, the $\delta^{18} \mathrm{O}$ variations among the cements would correspond to a change of water $\delta^{18} \mathrm{O}$ composition of less than $2.5 \%$. For comparison, frequent recharge of soil water, at tropical high rainfall sites in Hawaii, caused $\delta^{18} \mathrm{O}$ variations of up to $4 \%$ on a threemonth time scale (Hsieh et al., 1998). Thus a $2.5 \%$ change would argue either for an open hydrological system sub- 
ject to frequent recharge and low evaporation or for a closed hydrological system.

Finally, the vertical superposition of silicification levels would have developed from the same water, with no or only weak evaporation of the soil water. This water would have recharged a lower water table subject to successive deepening in a closed hydrological system. This is in agreement with earlier conclusions based on $\delta^{30} \mathrm{Si}$ data (BasileDoelsch et al., 2005). Fibrous crypto-crystalline quartz of marine quartzites located along the path of the downward moving water table, as well as granular crypto-crystalline quartz in the higher silcrete levels (Basile-Doelsch et al., 2005), would have been the starting points from which the sequence of quartz polymorphs of the silcretes cements would have formed.

\section{Conclusion}

This study describes a new protocol for laser-fluorination analysis of the oxygen isotope composition of microscopic silica grains, with an external precision better than $\pm 0.15 \%$. The similarity of $\delta^{18} \mathrm{O}$ data obtained using the laser fluorination technique and the ion microprobe on pure size fractions of quartz suggests that both techniques are accurate.

Sandstone, chert and silcrete benefit from being analyzed with the ion microprobe because thin sections are easy to make, whereas separation of high purity quartz polymorphs is difficult, as demonstrated in this study. However the fluorination technique is a significant improvement for isotopic studies dealing with materials such as soil or biogenic oxides and silicates (e.g., diatoms and phytoliths). These materials are too small and often recovered in insufficient amount to be easily prepared for ion microprobe analysis. Until now they have been analyzed using conventional fluorination techniques. The use of the laser fluorination technique requires amount of sample only one-sixth the amount of sample required for conventional fluorination and analyses may be done in half the time.

Fibrous crypto-crystalline quartz could not be cleanly separated from detrital quartz using the separation techniques described here, whereas granular crypto-crystalline quartz is efficiently concentrated in the $<2-1 \mu \mathrm{m}$ size-fraction. Micro-crystalline quartz is best concentrated in the $2-5 \mu \mathrm{m}$ size fraction using our separation protocol. Direct $\delta^{18} \mathrm{O}$ analysis of these latter two phases avoids the errors inherent in previous studies of silcrete in which the isotopic composition of cement was estimated from isotopic analyses of bulk material and mass balance considerations.

In the sequence from Apt, $\delta^{18} \mathrm{O}$ values of overgrowths, granular crypto-crystalline quartz and micro-crystalline quartz and from one silcrete layer to another are similar $(26.66 \pm 1.36 \%$ o $)$. This result suggests that the silicification of all the mineralogical phases and from one layer to another (including from an upper pedogenic silcrete to a lower groundwater silcrete) occurred in the presence of waters of similar isotopic compositions. This implies either a closed or an open system subject to only weak evaporation.

\section{Acknowledgments}

This research was supported by UMR CEREGE-IRD and CEREGE. Thanks to M. Champenois and C. Rollion-Bard (CRPG, Nancy, France) for ion microprobe analyses, and to D. Borschneck (CEREGE) for XRD analyses. We are grateful to the GCA Associate Editor T. Chacko and to the reviewers F. Longstaffe and S. Savin who greatly improved the submitted manuscript.

\section{Associate editor: Thomas Chacko}

\section{References}

Abdel-Wahab, A., Salem, A.M.K., McBride, E.F., 1998. Quartz cement of meteoric origin in silcrete and nonsilcrete sandstones, Lower Carboniferous, Western Sinai, Egypt. J. Afr. Earth Sci. 27, 277-290.

Aléon, J., Chaussidon, M., Marty, B., Schüt, L., Jaenicke, R., 2002. Oxygen isotopes in single micrometer-sized quartz grains: Tracing the source of Saharan dust over long-distance atmospheric transport. Geochim. Cosmochim. Acta 66, 3351-3365.

Alexandre, A., Meunier, J.D., Llorens, E., Hill, S.M., Savin, S.M., 2004. Methodological improvement for investigating silcrete formation: petrography, FT-IR and oxygen isotope ratio of silcrete quartz cement, Lake Eyre Basin Australia. Chem. Geol. 211, 261-274.

Basile-Doelsch, I., Meunier, J.D., Parron, C., 2005. Another continental pool in the terrestrial silicon cycle. Nature 433, 399-402.

Bird, M.I., Longstaffe, F.J., Fyfe, W.S., Bildgen, P., 1992. Oxygen-isotope systematics in a multiphase weathering system in Haïti. Geochim. Cosmochim. Acta 56, 2831-2838.

Blatt, H., 1986. Oxygen isotopes and the origin of quartz. J. Sediment. Petrol. 57, 373-377.

Clayton, R.N., O‘Neil, J.R., Mayeda, T.K., 1972. Oxygen isotope exchange between quartz and water. J. Phys. Res. 77, 3057-3067.

Crespin, J., Alexandre, A. Sonzogni, C., Sylvestre, F., 2005. A new protocol for oxygen isotope analysis of authigenic and biogenic fine silica grains using laser extraction technique. In: seventh International Symposium on the Geochemistry of the Earth's surface (GES-7). Aix-en-Provence (France), August 23-27, 2005. Volume of abstracts, 529-533.

Eslinger, E., Mayer, L.M., Durst, T.L., Hower, J., Savin, S.M., 1973. An $\mathrm{X}$-ray technique for distinguishing between detrital and secondary quartz in the fine-grained fraction of sedimentary rocks. J. Sediment. Petrol. 43, 540-543.

Flörke, O., Graetsch, H., Martin, B., Röller, K., Wirth, R., 1991. Nomenclature of micro- and non-crystalline silica minerals, based on structure and microstructure. Neues Jahrb. Mineral. Abh. 163-1, 19-42.

Fouillac, A.M., Girard, J.P., 1996. Laser oxygen isotope analysis of silicate/oxide grain separates: evidence for a grain size effect? Chem. Geol. 130, 31-54.

Garlick, G.D., Epstein, S., 1967. Oxygen isotope ratios in coexisting minerals of regionally metamorphosed rocks. Geochim. Cosmochim. Acta 31, 181-214.

Girard, J-P., Deynoux, M., 1991. Oxygen isotope study of diagenetic quartz overgrowths from the Upper Proterozoic quartzites of western Mali, Taoudeni Basin: implications for conditions of quartz cementation. J. Sediment. Petrol. 61, 406-418.

Girard, J.-P., Munz, I.A., Johansen, H., Hill, S., Canham, A., 2001. Conditions and timing of quartz cementation in Brent reservoirs, Hild Field, North Sea: constrains from fluid inclusions and SIMS oxygen isotope microanalysis. Chem. Geol. 176, 73-92. 
Graham, C.M., Valley, J.W., Winter, B.L., 1996. Ion microprobe analysis of ${ }^{18} \mathrm{O} /{ }^{16} \mathrm{O}$ in authigenic and detrital quartz in the St. Peter Sandstone, Michigan Basin and Wisconsin Arch, USA: contrasting diagenetic histories. Geochim. Cosmochim. Acta 60, 5101-5116.

Gurenko, A.A., Chaussidon, M., Schmincke, H.-U., 2001. Magma ascent and contamination beneath one intraplate volcano: Evidence from $\mathrm{S}$ and $\mathrm{O}$ isotopes in glass inclusions and their host clinopyroxenes from Miocene basaltic hyaloclastites southwest of Gran Canaria (Canary Islands). Geochim. Cosmochim. Acta 65, 4359-4374.

Hsieh, J.C.C., Chadwick, O.A., Kelly, E.F., Savin, S.M., 1998. Oxygen isotopic composition of soil water: Quantifying evaporation and transpiration. Geoderma 82, 269-293.

Kirschner, D.L., Sharp, Z.D., 1997. Oxygen isotope analyses of finegrained minerals and rocks using the laser-extraction technique. Chem. Geol. 105, 109-115 (1997).

Knauth, L.P., Epstein, S., 1976. Hydrogen and oxygen isotope ratios in nodular and bedded cherts. Geochim. Cosmochim. Acta 40, 1095-1108.

Kolodony, Y., Epstein, S., 1976. Stable isotope gochemistry of deep sea cherts. Geochim. Cosmochim. Acta 40, 1195-1209.

Kolodony, Y., Chaussidon, M., Katz, A., 2005. Geochemistry of chert breccia. Geochim. Cosmochim. Acta 69, 427-439.

Labeyrie, L., Juillet, A., 1982. Oxygen isotopic exchageability of diatom valve silica; interpretation and consequences for paleoclimatic studies Geochim. Cosmochim. Acta 46, 967-975.

Lee, M., Savin, S.M., 1985. Isolation of digenetic overgrowths on quartz sand grains for oxygen isotopic analysis. Geochim. Cosmochim. Acta 49, 497-501.

Matsuhisa, Y., Goldsmith, J.R., Clayton, R.N., 1979. Oxygen isotopic fractionation in the system quartz-albite-anorthite-water. Geochim. Cosmochim. Acta 43, 1131-1140.

Parron, C., Guendon, J.L., 1985. Les altérites médiocrétacées de Provence (bauxites et ocres): caractères et relations paléogéographiques. Géologie de la France 2, 137-150.

Parron, C., Nahon, D., Fritz, B., Paquet, H., Millot, G., 1976. Désilicification et quartzification par altération des grè Albiens du
Gard. Modèles géochimiques de la genèse des dalles quartzitiques et silcrètes. Sci. Geol. Bull. 29 (4), 273-284.

Sabouraud, C., Parron, C., 1977. Néoformation de cristaux de quartz par des eaux météoriques dans lesfrès albiens du Gard. Mise en évidence par l'étude des inclusions des grains. C. R. somm. Soc. Géol. Fr. 6, 322324.

Savin, S.M., Epstein, S., 1970. The oxygen isotopic compositions of coarse grained sedimentary rocks and minerals. Geochim. Cosmochim. Acta 34, 323-329.

Sharp, Z.D., 1990. A laser-based microanalytical method for the in situ determination of oxygen isotope ratios of silicates and oxides. Geochim. Cosmochim. Acta 54, 1353-1357.

Sharp, Z.D., Durakiewicz, T., Migaszwski, Z.M., Atudorei, V.N., 2002. Antiphase hydrogen and oxygen isotope periodicity in chert nodules. Geochim. Cosmochim. Acta 66, 2865-2873.

Spicuzza, M.J., Valley, J.W., Kohn, M.J., Girard, J.P., Fouillac, A.M., 1998. The rapid heating, defocused beam technique: a $\mathrm{CO}_{2}$-laser-based method for highly precise and accurate determination of $\delta^{18} \mathrm{O}$ values of quartz. Chem. Geol. 144, 195-203.

Sprunt, E.S., Nur, A., 1981. Causes of quartz cathodoluminescence color. Scan. Electron Microsc. 1, 525-535.

Thiry, M., Millot, G., 1987. Mineralogical forms of silica and their sequence of formation in silcretes. J. Sediment. Petrol. 57, 343-352.

Triat, J.M., Parron, C., 1976. L'ocrification des sables glauconieux albocénomaniens du Gard et du Vaucluse. Bull. Soc. Geol. Fr. XVIII-1, 2125.

Valley, J.W., Kitchen, N., Kohn, N., Niendorf, M.J., Spicuzza, M.J., 1995. UWG_2, a garnet standard for oxygen isotope ratios: strategies for high precision and accuracy with laser heating. Geochim. Cosmochim. Acta 59, 5223-5231.

Watchman, A.L., Twidale, C.R., 2002. Relative and 'absolute' dating of land surfaces. Earth-Sci. Rev. 58, 1-49.

Webb, J.A., Golding, S.D., 1998. Geochemical mass-balance and oxygenisotope constraints on silcrete formation and its paleoclimatic implications in Southern Australia. J. Sediment. Res. 68, 981-993. 